\title{
Endosonography for rectal carcinoma: Preoperative TNM staging compared to histology
}

TL TIO, MD, PHD, PPLO COENE, MD

\begin{abstract}
Transrectal endosonography was performed preoperatively in 58 patients with rectal carcinoma. The results of endosonography were compared to the histology of resected specimens according to the new (1987) TNM (tumour, nodes, metastases) classification. Endosonography was accurate in the staging of tumour categories except with T 2 carcinomas because of concomitant peritoneal abscesses, inflammation or tissue changes after irradiation therapy. The overall accuracy of endosonography was $81 \%$. Overstaging occurred in $17 \%$ and understaging in $2 \%$. The accuracy of endosonography for staging regional lymph nodes was $74 \%$, sensitivity was $95 \%$ and specificity $61 \%$. Endosonography was not accurate in the staging of distant metastases due to the limited penetration depth of ultrasound used. In conclusion, endosonography will become the standard for staging rectal carcinoma. Can J Gastroenterol 1990;4(9):537-541
\end{abstract}

Key Words: Endosonography, Histology, Rectal carcinoma, TNM staging

\section{L'endosonographie et le cancer du rectum: La classification pTNM comparée à l'histologie}

RESUME: L'endosonographie transrectale a été effectuée au stade préopératoire chez 58 patients atteints de cancer du rectum. Les résultats de l'endosonographie ont été comparés à l'histologie des pièces de résection selon la nouvelle classification TNM (1987). L'endosonographie s'est avérée exacte dans la classification des tumeurs selon la taille, à l'exception des cancers T2 (à cause de la présence d'abcès péritonéaux concomitants, d'une inflammation ou de changements tissulaires post-radiques). L'exactitude globale de l'endosonographie était de $81 \%$. La classification était surestimée dans $17 \%$ et sous-estimée dans $2 \%$ des cas. En ce qui touche l'extension aux ganglions lymphatiques, la précision de la classification atteignait 74\%, la sensibilité $95 \%$ et la spécificité $61 \%$. A cause de la capacité de pénétration limitée des ultrasons utilisés, l'endosonographie était imprécise dans la classification des métastases à distance. En conclusion, l'endosonographie est en passe de devenir la technique standard de classification des cancers du rectum.

Academic Medical Center, Department of Gastroenterology-Hepatology, Amsterdam, The Netherlands

Correspondence and reprints: Dr TL Tio, Academic Medical Centre, Department of Gastroenterology-Hepatology, Meibergdreef 9, 1105 AZ Amsterdam, The Netherlands, Telephone 020-566-9111, Fax 020-566-4400
$E$ NDOSCOPY IS ACCURATE IN DIAGnosing rectal carcinoma. The submucosal extent of the tumour, however, cannot be assessed. Even computed tomography is not accurate for staging rectal carcinoma because of inability to image the individual layers of the rectal wall $(1,2)$. Endoscopic and nonoptic sonography, generally known as endosonography, were developed to improve the diagnostic value of ultrasound by directly approaching the target lesion via the gastrointestinal lumen with a high frequency ultrasonic beam (3-8). This technique has been reported to be accurate for clinical TNM (tumour, nodes, metastases) staging of gastrointestinal carcinoma (9-13).

Recently, there has been a revision of the $\mathrm{T}$ categories and stage grouping of the TNM classification, which now permits a direct translation to Duke's classification (14-17). The $\mathrm{N}$ classification has been revised to account for the lymph nodes as well as their location. These changes were made based on data from the Erlangen Tumor Registry (16). The aim of this study was to assess the accuracy and limitations of transrectal endosonography in clinical TNM staging of rectal carcinoma according to the new (1987) TNM classification.

\section{MATERIALS AND METHODS}

Between March 1984 and April 1989 endosonography was performed 
preoperatively in 58 patients with rectal carcinoma proven by endoscopic biopsy. There were 40 males and 18 females with ages ranging from 26 to 90 years (average 66). These examinations were performed within four weeks before surgery. The results of endosonographic images and histology of resected specimens were staged according to the new (1987) TNM classification.

Instruments: The author has been routinely using the rigid Aloka ASU-59 and a flexible Aloka prototype ASU-57 to examine the rectal carcinomas (Figure 1). For rectosigmoid colon, the author has been using the side-viewing $10 \mathrm{MHz}$ echoendoscope (EUM2) or the forward-viewing echocoloscope (AXFEUM2). The latter can be more readily maneuvred endoscopically because of its forward-viewing optics (Figure 2). This radial scanner has a sector of approximately $300^{\circ}$ because the biopsy channel adjacent to the transducer hampers the transmission of ultrasound. The area under the biopsy channel cannot be seen due to the total reflection

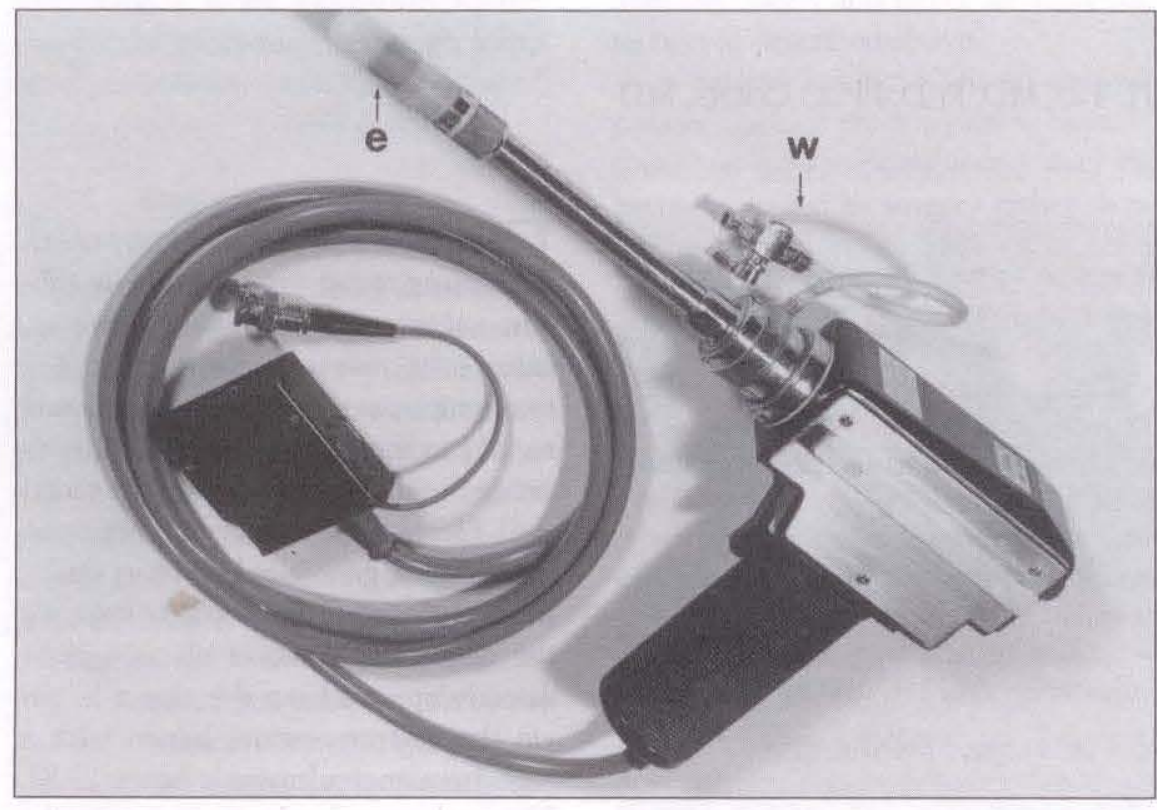

Figure 1) A rigid Aloka ultrasonic instrument (ASU-57) with an echoprobe (e) attached at the tip of the rigid shaft. $w$ Water channel for filling with water the balloon attached at the transducer

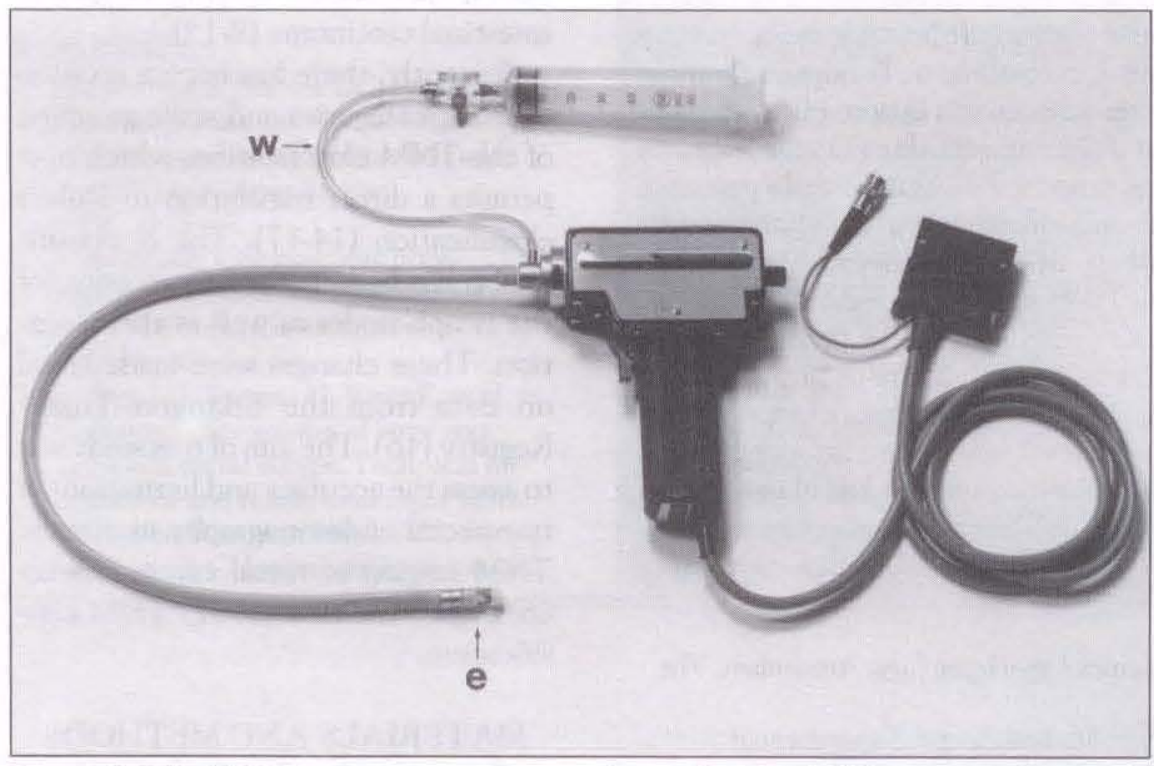

Figure 2) A flexible Aloka prototype instrument with a small echoprobe (e) attached at the tip of the flexible shaft of the ultrasonic beam. The recently available Olympus echoendoscope can be attached with a water-filled balloon at the transducer (Figure 3). This makes imaging of colorectal abnormalities much easier. The specifications of these instruments are summarized in Table 1. Investigation technique: The technique of investigation is compatible with rectosigmoidoscopy in patients lying in the left lateral decubitus position after phosphate enema. Rectal digital examination is obligatory to assess the local anatomy and to dilate the sphincter and muscle prior to insertion of the instrument. The nonoptic instrument is blindly inserted as deeply as possible. Thereafter, the instrument should carefully be withdrawn until ab. normalities are imaged sonographically. By filling the balloon with water the polypoid or exophytic configuration of tumours can be clearly visualized. The method of investigation with the echoendoscope is similar to the examination of the stomach for gastric carcinomas.

The tumour should be visualized endoscopically. The echoprobe is positioned adjacent to the tumour. Thereafter, the balloon or the colorectal lumen is filled with water to produce adequate transmission for ultrasound. Whenever possible, the instrument should be passed beyond the lesion into the proximal colonic segments to visualize lymph node abnormalities and to determine the proximal noninfiltrated area. This is important to give accurate information for localization of resection margins. The interpretation of normal and pathological structures is based on the results of previous studies. Endosonographic criteria for new TNM staging are given in Table 2.

Criteria for assessing lymph node metastases are as follows. Lymph nodes with a hypoechoic pattern and clearly delineated boundaries are suspicious of malignancy. Direct extension of mural abnormalities into adjacent lymph nodes is highly suspicious of malignancy. Lymph nodes with a hyperechoic pattern and indistinctly demarcated boundaries are indicative of benignancy.

Staging of distant metastasis with endosonography was excluded because 


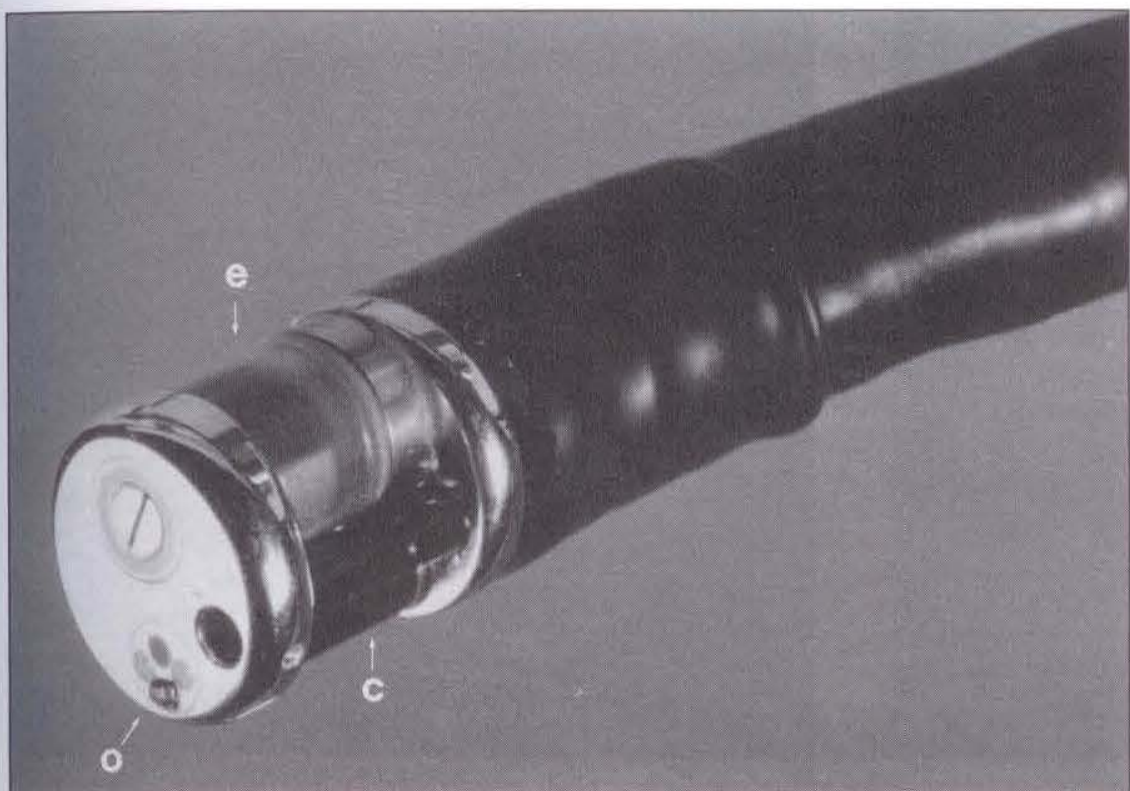

Figure 3) An Olympus prototype echocoloscope (AXF-EUM2) with a small echoprobe (e) attached beyond forward-viewing optics (o) adjacent to the biopsy channel (c)

TABLE 1

Technical data of various colorectal echoendoscopes

\begin{tabular}{|c|c|c|c|c|}
\hline Echoendoscope & $\begin{array}{l}\text { Olympus } \\
\text { EU-M2 }\end{array}$ & $\begin{array}{l}\text { Olympus } \\
\text { AXF-EUM2 }\end{array}$ & $\begin{array}{c}\text { Aloka ASU-57 } \\
\text { flexible }\end{array}$ & $\begin{array}{c}\text { Aloka ASU-59 } \\
\text { rigid }\end{array}$ \\
\hline Endoscope & $\begin{array}{l}\text { Side-viewing } \\
\text { duodenoscope }\end{array}$ & $\begin{array}{c}\text { Forward-viewing } \\
\text { coloscope }\end{array}$ & Nonoptic & Nonoptic \\
\hline Length & $120 \mathrm{~cm}$ & $130 \mathrm{~cm}$ & $65 \mathrm{~cm}$ & $5 \mathrm{~cm}$ \\
\hline $\begin{array}{l}\text { Echoprobe } \\
\text { length }\end{array}$ & $42 \mathrm{~mm}$ & $42 \mathrm{~mm}$ & $10 \mathrm{~mm}$ & $40 \mathrm{~mm}$ \\
\hline Diameter & $13 \mathrm{~mm}$ & $15 \mathrm{~mm}$ & $10 \mathrm{~mm}$ & $15 \mathrm{~mm}$ \\
\hline Frequency & $10 \mathrm{MHz}$ & $7.5 \mathrm{MHz}$ & $7.5 \mathrm{MHz}$ & $5 \mathrm{MHz}$ \\
\hline $\begin{array}{l}\text { Depth of } \\
\text { penetration }\end{array}$ & $5 \mathrm{~cm}$ & $10 \mathrm{~cm}$ & $10 \mathrm{~cm}$ & $22 \mathrm{~cm}$ \\
\hline Axial resolution & $0.15 \mathrm{~mm}$ & $0.2 \mathrm{~mm}$ & $0.2 \mathrm{~mm}$ & $0.5 \mathrm{~mm}$ \\
\hline
\end{tabular}

Allechoprobes are mechanical sector or radial scanning $\left(180^{\circ}\right.$ or $\left.360^{\circ}\right)$. Only the Olympus AXF-EUM2 has capability for endoscopically guided puncture or biopsy

\section{TABLE 2}

\section{Endosonographic criteria for 1987 TNM staging of rectal carcinoma}

\section{Assessment of rectal carcinoma}

Il Hypoechoic tumour localized in the mucosa and/or submucosa

T2 Hypoechoic tumour invades the muscularis propria

T3 Hypoechoic fumour invades through the muscularis propria into the subserosa or nonperitonealized pericolic or perirectal tissues

I4 Hypoechoic tumour penetrates the visceral peritoneum or directly invades other organs or structures.

Assessment of lymph node metastasis of rectal carcinoma

N Regional lymph nodes

NO No regional lymph node metastasis

N1 Metastasis in one or three perirectal or pericolic lymph nodes

N2 Metastasis in four or more perirectal or pericolic lymph nodes

N3 Metastasis along the course of a named vascular trunk.

Assessment of distant metastasis of rectal carcinoma

$M$ Distant metastasis

MO No distant metastasis

MI Distant metastasis such as hepatic and/or peritoneal dissemination
TABLE 3

Results of histology and endosonography in assessing depth of fumour infiltration of colorectal carcinoma

\begin{tabular}{lcc}
\hline Stage & Histology & Endosonography \\
\hline T1 & 7 & 5 \\
T2 & 15 & 7 \\
T3 & 34 & 34 \\
T4 & 2 & 1 \\
\hline
\end{tabular}

Values given are numbers of patients. There were two and eight patients overstaged in the $T I$ and $T 2$ classes, respectively, and one patient understaged in the T4 class. (For explanations of $T$ categories, see Table 2)

\section{TABLE 4}

Results of histology and endosonography in assessing regional lymph nodes of colorectal carcinoma

\begin{tabular}{lcc}
\hline Stage & Histology & Endosonography \\
\hline NO & 36 & 22 \\
N1 & 13 & $8\left(4^{*}\right)$ \\
N2 & 9 & $7\left(2^{*}\right)$ \\
N3 & - & - \\
\hline
\end{tabular}

There were 14 false positives in the NO class and one false negative in the NI class. "Patients with inaccurate staging according to the separate N1 and N2 definitions of metastasis. Values given are numbers of patients. (For explanations of $N$ categories, see Table 2)

lymph node metastasis along the suprarectal blood vessels, liver metastasis and peritoneal dissemination could not be imaged. This was explained by the limited penetration depth of ultrasound and the difficult anatomical route to reach the target of interest.

\section{RESULTS}

Table 3 summarizes the results of endosonography and histology in assessing the depth of tumour infiltration. The depth of tumour infiltration was assessed in 58 patients.

T1 carcinoma was correctly diagnosed in five of seven patients. Overstaging occurred in two patients due to peritumoral infiltration.

T2 carcinoma was correctly diagnosed in seven of 15 patients (Figure 4). Overstaging occurred in eight patients due to perirectal abscesses (three patients), peritumoral inflammation (four patients) or preoperative irradiation with destruction of peritumoral structures (one patient). 

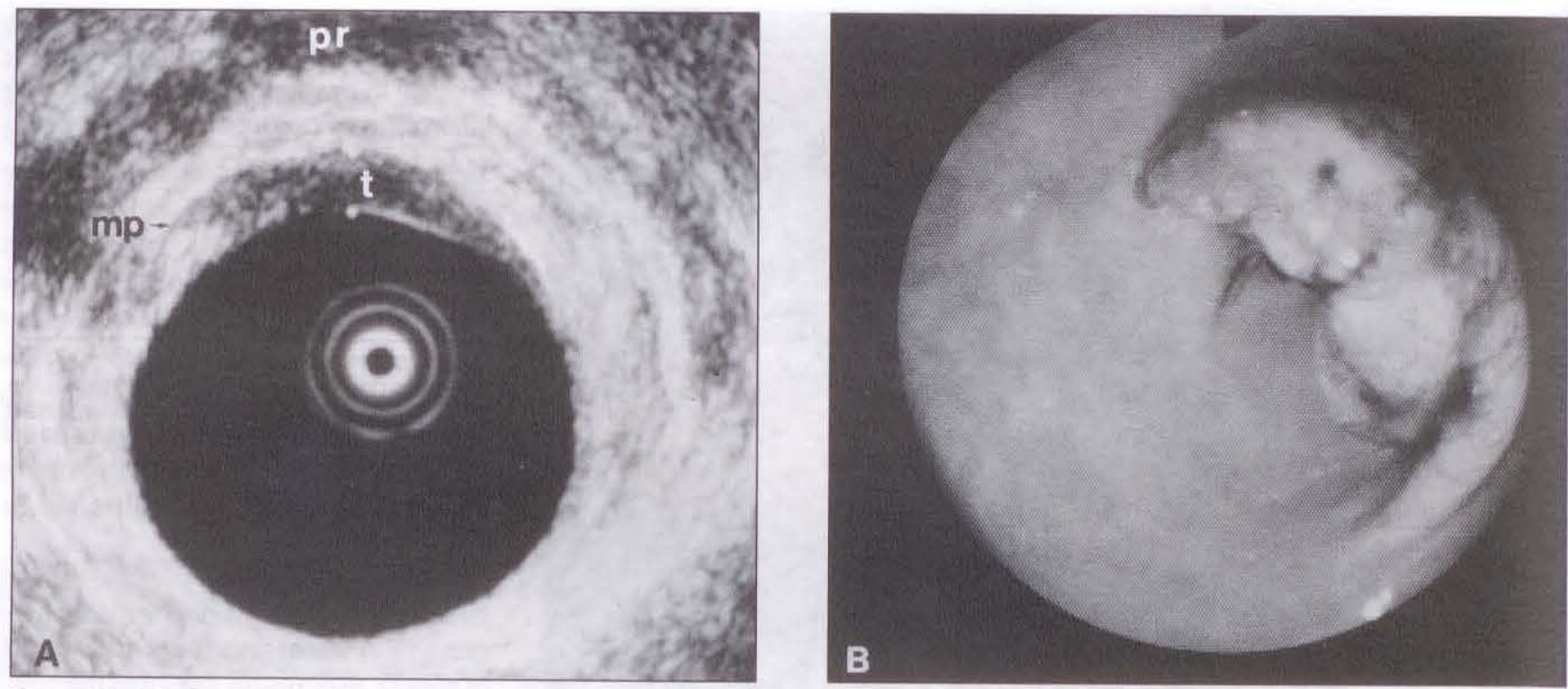

Figure 4) A Endosonogram of a hypoechoic rectal carcinoma $(t)$ with penetration into the muscularis propria ( $m p$ ) localized ventrally adjacent to the prostate gland ( $p r)$. B Corresponding endoscopy showing a polypoid tumour
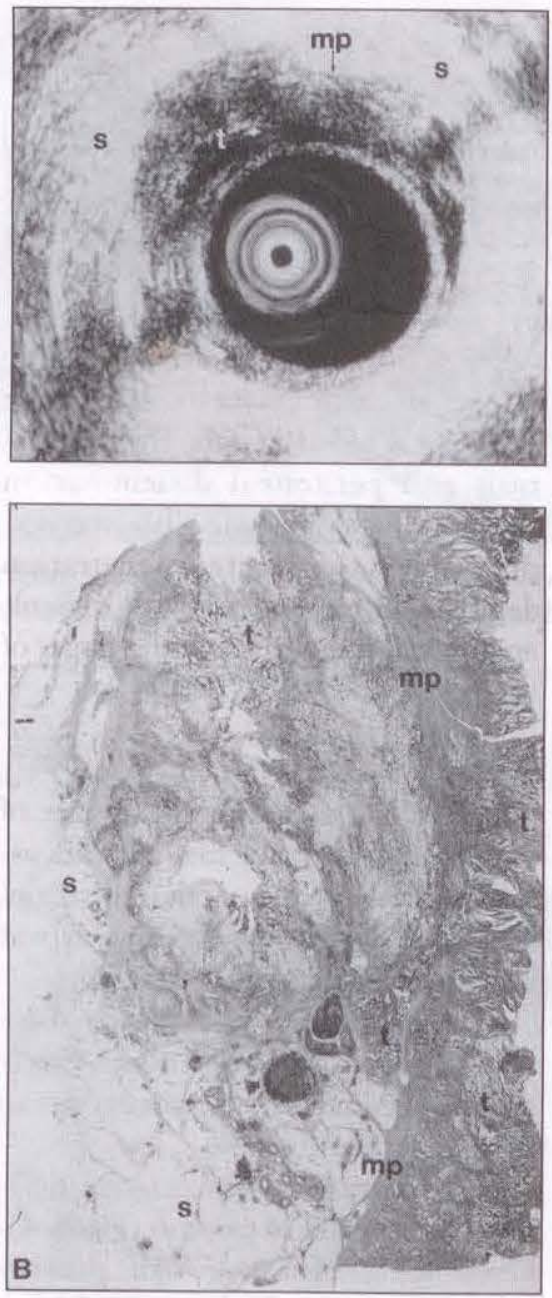

Figure 5) A Endosonogram of a hypoechoic tumour $(t)$ with penetration through the muscularis propria $(m p)$ into the submucosal layer (s). B Corresponding histology of carcinoma penetrated through the muscularis propria (mp)
T3 carcinoma was correctly diagnosed in all 34 patients (Figure 5). T4 carcinoma was correctly diagnosed in one of two patients. Understaging occurred in one patient because penetration into the dorsal wall of the vagina was not imaged.

The overall accuracy was $81 \%$. Overstaging occurred in $17 \%$ and understaging in $2 \%$.

Table 4 summarizes the results of endosonography and histology in assessing regional lymph nodes. The number of lymph nodes in one resected specimen varies from one to 17 with a total of 337 (average per resected specimen six). Metastases (N1 and N2) were found in 114 lymph nodes (34\%). Nonmetastatic tumours (diameter range 2 to $18 \mathrm{~mm}$ ) were correctly diagnosed in 22 of 36 patients. Incorrect diagnoses were made in the remaining 14 patients. Lymph node metastases (diameter range 6 to $22 \mathrm{~mm}$ ) were correctly diagnosed in 21 of 22 patients. False negative diagnoses were made in the remaining patient due to granulomatous inflammation. However, accurate staging according to the separate $\mathrm{N} 1$ and N2 definitions of metastasis was done in only 15 patients: N1 metastasis was correctly staged in eight of 13 patients and N2 in seven of nine patients. N1 metastasis was erroneously classified as N2 in four patients and N2 as N1 in two. The overall accuracy of endosonography was $74 \%$, sensitivity $95 \%$ and specificity $61 \%$. The positive predictive value was $60 \%$ and negative was $96 \%$.

\section{DISCUSSION}

Endosonography is accurate in the assessment of tumour category because of the ability to image the depth of tumour infiltration and transition between normal and pathological wall structure. A close correlation between endosonography findings and histology can be demonstrated. Various sections of endosonography images are crucial for the assessment of maximal depth and extent of carcinomatous infiltration. This is essential for comparing the clinical T category with the pathological T category. Overstaging may occur because of peritumoral inflammation, which cannot be distinguished from carcinomatous infiltration on ultrasound. Understaging may occur due to severe stenosis, which cannot be passed with the instrument.

Endosonography is more accurate for determining metastatic involvement than for identifying nonmetastatic lymph nodes. Distinction between a micrometastatic and a benign lymph node or between an inflammatory enlarged lymph node and lymph node metastasis cannot be made based on ultrasound alone. Therefore, false positive and false negative diagnoses may occur. 
Stage grouping is a combination of $\mathrm{T}, \mathrm{N}$ and $\mathrm{M}$ categories. Therefore, stage grouping can be assessed if additional transcutaneous ultrasound or computed tomography is incorporated. Incorrect diagnosis of each category, however, may lead to erroneous stage grouping. This has also been reported in the staging of upper gastrointestinal carcinomas (9-13).

In conclusion, the author believes that endosonography will become the standard procedure for staging rectal carcinomas. The important information for the surgeon is the delineation of the tumour free region, both proximal and distal to the primary site. Moreover, lymph nodes adjacent to and distant from the edge of tumour should be carefully examined. With this information, radical tumour resection and lymph node dissection can be planned. In cases of nonsurgical treatment with laser photocoagulation or irradiation, the depth of tumour infiltration before and after treatment should be carefully measured. In this manner, documentation after therapy can be done.

\section{REFERENCES}

1. Romano G, de Rossa P, Vallone G, Rotondo A, Grassi R, Santangelo ML. Intrarectal ultrasound and computed tomography in the pre-and post-opera- tive assessment of patients with rectal carcinoma. Br J Surg 1985;72 (Suppl):117-9.

2. Beyon J, Montenson NJ, Foy DM, Channer JL, Virjee J, Oddard PP. Preoperative assessment of local invasion in rectal cancer: Digital examination, endoluminal sonography or computed tomography? Br J Surg 1986;73:1015-7.

3. Saitoh N, Okui K, Sarahina H, Suzuki M, Azai T, Nunomusa M. Evaluation of echographic diagnosis of rectal cancer using intrarectal ultrasonic examination. Dis Colon Rectum 1986;29:234-42.

4. Hildebrandt U, Feifel G. Preoperative staging of rectal cancer by intrarectal ultrasound. Dis Colon Rectum 1985;28:42-6.

5. Konishi F, Muto T, Takahashi H, Itoh K, Kanazawa K, Morioka Y. Transrectal ultrasonography for the assessment of invasion of rectal carcinoma. Dis Colon Rectum 1985;28:889-94.

6. Tio TL, Tytgat GNJ. Atlas of Transintestinal Ultrasonography. Aalsmeer: Mur-Kostverloren, 1986.

7. Tio TL. Endosonography in Gastroenterology. Heidelberg: Springer Verlag, 1988.

8. Tio TL, Tytgat GNJ. Comparison of blind transrectal ultrasonography with endoscopic transrectal ultrasonography in assessing rectal and perirectal diseases. Scand J Gastroenterol 1986;21(Suppl 123):104-11.

9. Tio TL, Cohen P, Coene PP, Udding J, den Hartog Jager FCA, Tytgat GNJ. Preoperative TNM classification of esophageal carcinoma by endosonography and computed tomography. Gastroenterology 1989;96:1478-86.

10. Tio TL, Schouwink MH, Cikot R, Tytgat GNJ. Preoperative TNM classification of gastric carcinoma by endosonography in comparison with the pathological TNM system: A prospective study of 72 cases. Hepatogastroenterology 1989;36:51-6.

11. Tio TL, Coene PPLO, Schouwink $\mathrm{MH}$, Tytgat GNJ. Esophagogastric carcinoma: Preoperative TNM classification with endosonography. Radiology 1989;73:411-7.

12. Tio TL, Tytgat GNJ, Cikot RJLM, Houthoff HJ. Ampullopancreatic carcinoma: Preoperative TNM classification with endosonography. Radiology 1990;175:455-61.

13. Tio TL, Wijers OB, Sars PRA, Tytgat GNJ. Preoperative TNM classification of proximal extrahepatic bile duct carcinoma with endosonography. Semin Liver Dis 1990;10:114-20.

14. Dukes CE, Bussey HJR. The spread of rectal cancer and its effect on prognosis. Br J Cancer 1958;12:309-20.

15. Hermanek P, Sobin LH. TNM Classification of Malignant Tumours. International Union Against Cancer, 4th edn. Berlin: Springer Verlag, 1987:479.

16. Sobin LH, Hermanek P, Hutter RP. TNM classification of malignant tumours. Cancer 1988;61:2310-4.

17. Spiessl B, Beahrs OH, Hermanek P, et al. TNM Atlas. International Union Against Cancer. Berlin: Springer Verlag, 1989:118-33. 


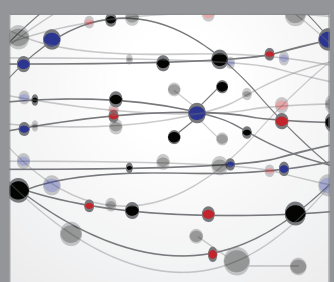

The Scientific World Journal
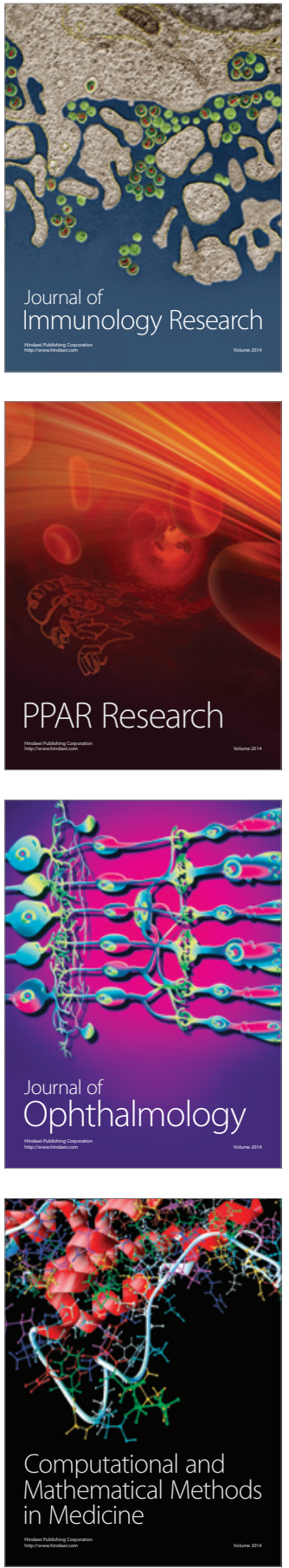

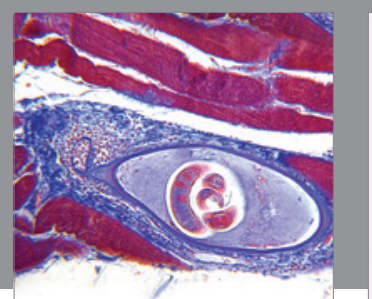

Gastroenterology Research and Practice

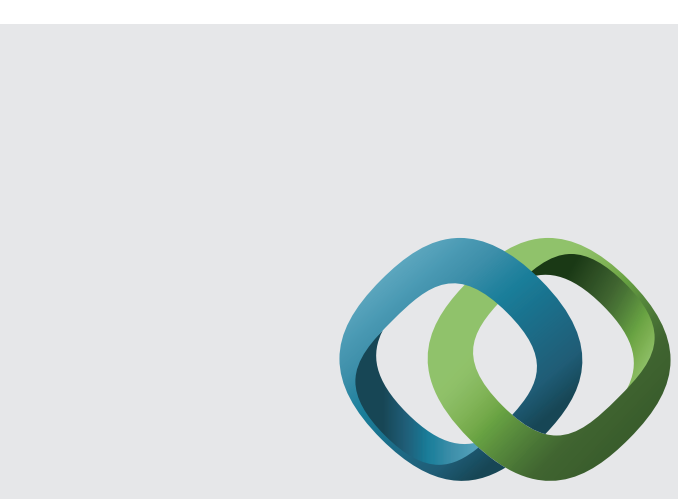

\section{Hindawi}

Submit your manuscripts at

http://www.hindawi.com
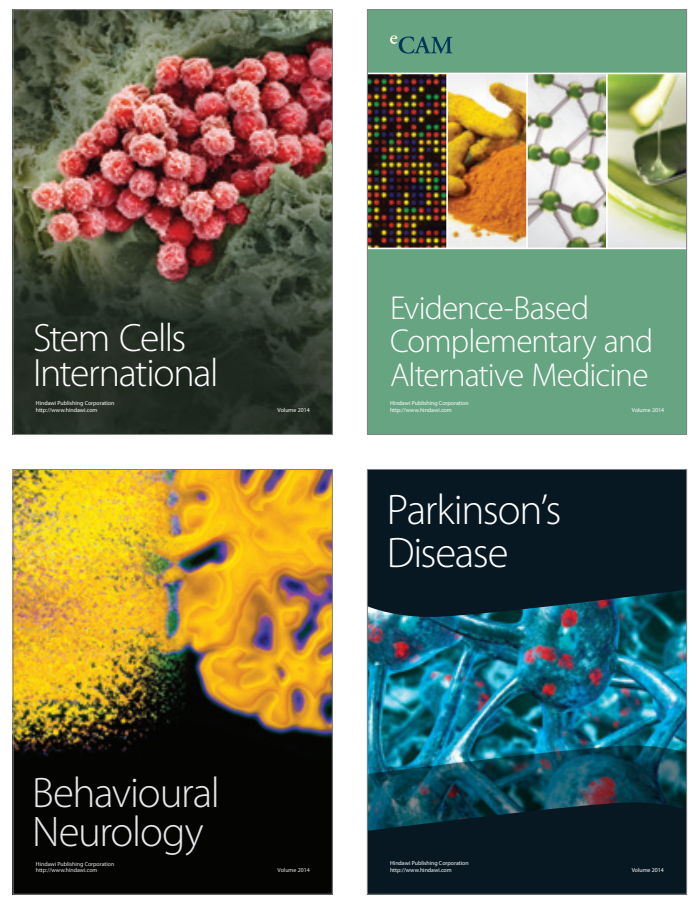
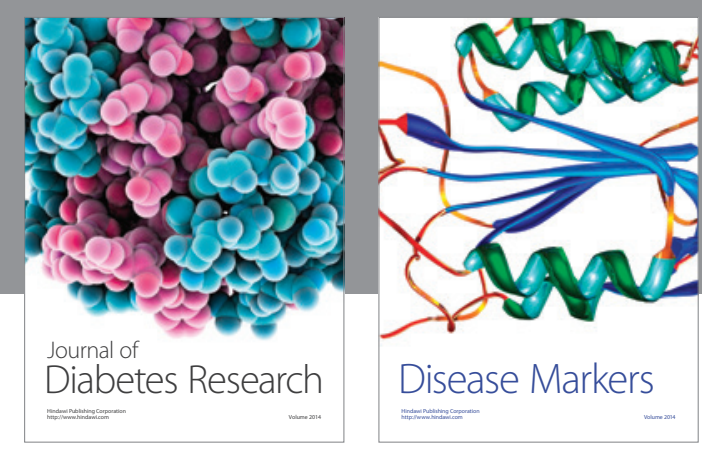

Disease Markers
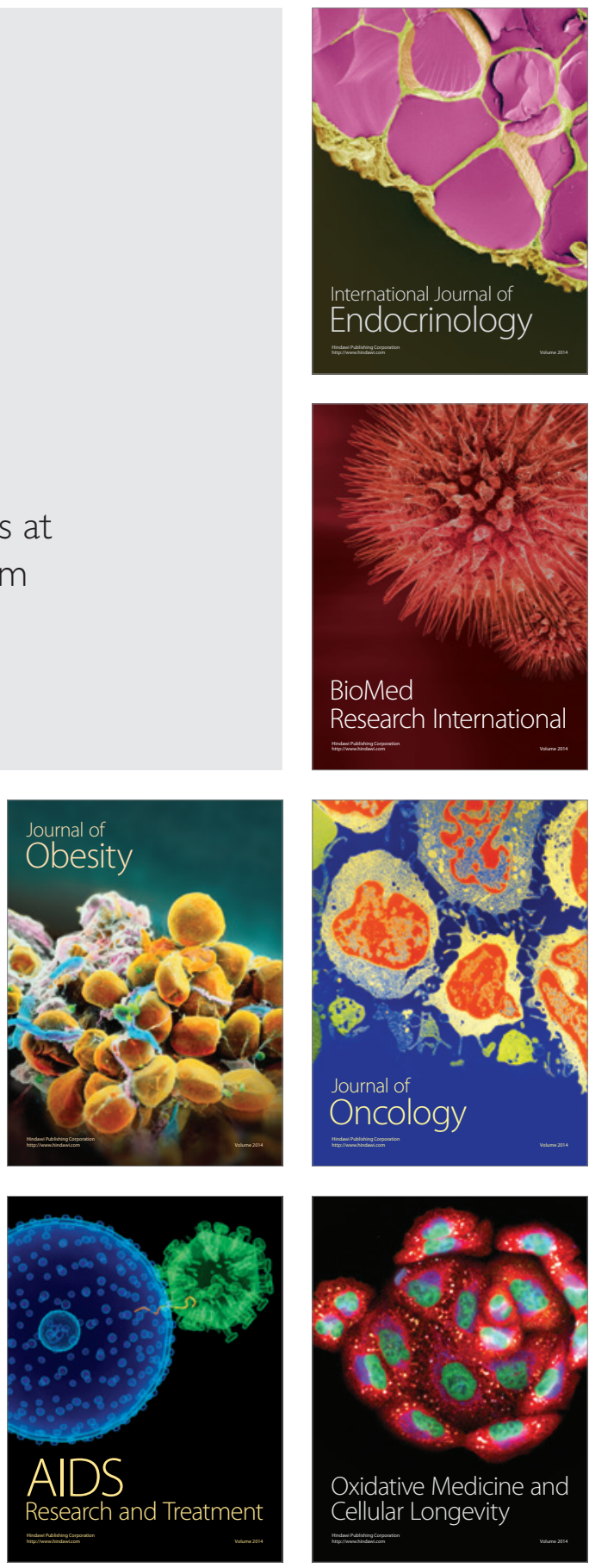